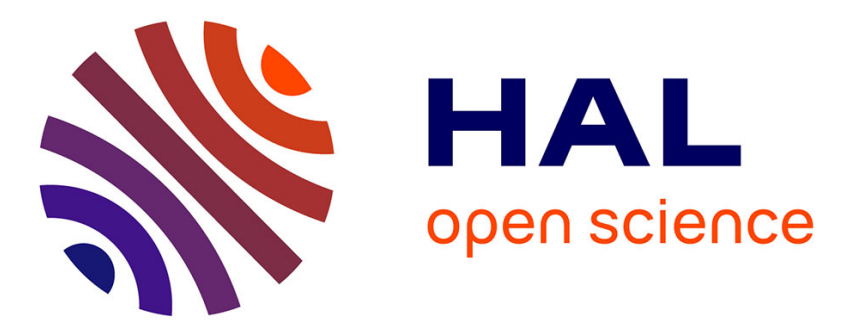

\title{
Renewable Photopolymer Films Derived from Low-Grade Lampante and Pomace Olive Oils
}

Khaled Bouaziz, Mohamed Ayadi, Noureddine Allouche, Abraham Chemtob

\section{To cite this version:}

Khaled Bouaziz, Mohamed Ayadi, Noureddine Allouche, Abraham Chemtob. Renewable Photopolymer Films Derived from Low-Grade Lampante and Pomace Olive Oils. European Journal of Lipid Science and Technology, 2017, Euro Fed Lipid Highlights 2017, 119 (12), pp.1700003. 10.1002/ejlt.201700003 . hal-02442164

\section{HAL Id: hal-02442164 \\ https://hal.science/hal-02442164}

Submitted on 16 Jan 2020

HAL is a multi-disciplinary open access archive for the deposit and dissemination of scientific research documents, whether they are published or not. The documents may come from teaching and research institutions in France or abroad, or from public or private research centers.
L'archive ouverte pluridisciplinaire HAL, est destinée au dépôt et à la diffusion de documents scientifiques de niveau recherche, publiés ou non, émanant des établissements d'enseignement et de recherche français ou étrangers, des laboratoires publics ou privés. 


\title{
Renewable Photopolymer Films Derived from Low-Grade Lampante and Pomace Olive Oils
}

\author{
Khaled BOUAZIZ ${ }^{1}$, Mohamed AYADI ${ }^{2}$, Noureddine ALLOUCHE ${ }^{1}$, Abraham CHEMTOB $^{3 *}$ \\ ${ }^{1}$ Laboratoire de Chimie des Substances Naturelles (UR11-ES74), Université de Sfax, Faculté des \\ Sciences de Sfax, département de chimie B.P. 1171, C.P. 3000, Sfax, Tunisie. \\ ${ }^{2}$ Institut de l'Olivier, Route de l'Aéroport, 3000, Sfax, Tunisie. \\ ${ }^{3}$ Institut de Science des Matériaux de Mulhouse, CNRS UMR 7361, 15 rue Jean Starcky, 68057 \\ Mulhouse, France
}

Running Title: New exploitation of low grade olive oils.

*Corresponding author:abraham.chemtob@uha.fr
Abbreviations:
FA Fatty acid
$\mathrm{Hg}-\mathrm{Xe} \quad$ Mercury-Xenon
IR Infrared
MCT Mercury-cadmium-telluride
RT-FTIR Real-time Fourier transform infrared spectroscopy
UV Ultraviolet 


\begin{abstract}
Thiol-ene photoinduced copolymerization between a polythiol cross-linker and low grade unsaturated olive oil provides an eco-efficient route to dry, flexible and rubbery films in the matter of minutes. The synthetic methodology uses low cost olive oils resulting from nonedible grades (lampante olive oil) and waste production (pomace olive oil) without prior chemical modification. The resultant photopolymer thioether cross-linked films contain up to 80-85\% of renewable resources, and UV-driven drying proceeds despite the limited unsaturations' concentration. Photopolymerization is triggered with a conventional mediumpressure mercury lamp in presence of three different thiol cross-linkers: 2,2'(ethylenedioxy)diethanethiol, hexanedithiol or trimethylolpropanetris(3-mercaptopropionate) and a radical photoinitiator (2-hydroxy 2-methylpropiophenone). Using real-time Fourier transform infrared spectroscopy (RT-FTIR), we show that cross-linking proceeds essentially via a step-growth thiol-ene polymerization, and to a minor extent, by a conventional photooxidation mechanism.
\end{abstract}

\title{
Practical Applications
}

Olive oil is the second largest produced vegetable oil, and in 2016 world production amounted to 3.5 million tons. An excess of low-grade pomace and lampante olive oils is generated annually from the conventional extraction process; however, declared unfit for human consumption, they have a limited number of uses, and it is difficult to find new outlets. Despite this excess, the development of synthetic and processing methods to convert these non-edible olive oils in useful materials has not been investigated widely. Here we report a method based on thiol-ene photopolymerization to prepare a new range of UV-curable films. Using time-resolved infrared spectroscopy, this study sheds light into reaction kinetics and polymerization mechanism.

Keywords: Ultra-violet, photopolymerization, auto-oxidation, thiol-ene, infrared spectroscopy. 


\section{Introduction}

Radiation curing is widely regarded as an emerging technology for the eco-efficient production of organic polymer films. Starting from a liquid film containing oligomers and multifunctional monomers still largely dependent on fossil resources (oil, gas, etc.), exposure to UV or visible light in the presence of a photoinitiator triggers a cross-linking reaction to create a solid network film, ideally both hard and chemically resistant [1]. The appeal of this curing method relies on a unique combination of solvent-free condition, reaction at room temperature, fast cycle times of less than one second, and small-scale production lines. Applications span a large range of sectors, not only in industrial coatings, but also graphic arts and adhesives. Today, the economy of UV-curable coatings grows at a sustained high rate of $9 \%$ per year [2]. An exceptional value when compared with that of waterborne coatings (3\%) or powder coatings $(2 \%)$ produced by other energy-efficient technologies.

With the push for businesses to improve their green credentials, the radiation curing industry has embarked on a process aimed at incorporating an increasing part of bio-based monomers or oligomers into the photocurable formulation [3-6]. Foremost amongst the sustainable resources are vegetable oils which boast functionality, non-toxicity, straightforward extraction and wide source of supply [7, 8]. For reasons of reactivity, the main emphasis has been on structures based on unsaturated triglyceride esters of fatty acids [9]. Because the internal carbon double bonds are generally not reactive enough towards most photopolymerization processes, the main solution has consisted in a preliminary chemical modification. Epoxidation is the simplest way to make plant oils reactive via cationic photopolymerization [10], while (meth)acrylation is a multi-step reaction enabling their use in free radical photopolymerization [11]. Additionally, oils with a high ratio of unsaturations can be photocured under daylight or UV irradiation through a photo-oxidation mechanism accelerated by metallic salt catalyst $[12,13]$. Photoinduced thiol-ene reaction is the last strategy which has been extensively investigated over the last 10 years [14]. Nevertheless, most studies use thiolene as a functionalization tool of unsaturated plant oils or fatty acid derivatives [15-17] rather than for cross-linking [18, 19]. The thiol-ene polymerization reaction is a free radically initiated reaction of a thiol adding to an unsaturation of the triglyderide. It proceeds through a stepwise mechanism in which a photo generated thiyl radical reversibly adds to an unsaturation, producing a carbon radical able to abstract a new hydrogen from a thiol, and thus ensuring the polymerization propagation [20]. Thiol-ene photopolymerization using polyfunctional thiol cross-linkers was reported in a limited number of studies [18, 19, 21, 22]. 
All these studies involve modified oils (acrylate, maleate, fumarate, vinyl ether) to enhance reactivity because internal olefins of unmodified fatty acids are approximately 10 times less reactive than terminal ones toward the addition [23]. Furthermore, most employed oils, including linseed or soybean oil, contain a high concentration of unsaturations, although their role is also crucial in human and animal consumption.

By contrast, we have focused our attention on thiol-ene photopolymerization of native (nonmodified) triglycerides with the emphasis on low-grade unsaturated plant oils. Lampante and pomace olive oils are two emblematic examples. Their structure and average composition in fatty acids are given in Scheme 1, this latter does not strongly differ from those of virgin olive oil. In green polymerization methods, olive oil has been generally ruled out because of its major role in human diet, and its high cost compared to other seed oils. Nonetheless, the situation is clearly different for these two systems:

- Lampante olive oil is defined as a low quality olive oil because of lack of care, parasites or diseases. It is declared unfit for human consumption because of acidity problems and high concentrations of polycyclic aromatic hydrocarbons [25]. Locally, many small producers are producing lampante oil because of inadequate tools or improper installation. Despite the technical developments of the last 10 years, this category reaches between 10 and $20 \%$.

-The extraction of virgin olive oil also results in the production of solid by-products called olive oil cake, consisting of the dry matter of the olive (pulp, peel, stone...). When it is not used for livestock feeding or energy recovery [24], the olive cake is dried, grinded and treated with solvent, usually hexane, to produce a flavor-less pomace olive oil. About $20 \%$ of olive oil is actually entrapped in the cake, meaning that it represents an under-exploited resource.

This study demonstrates the applicability of an eco-efficient thiol-ene photopolymerization to produce dry rubbery films with low cost olive oils resulting from non-edible grades (lampante) and waste production (pomace) without prior chemical modification. The resulting UV-curable films contain up to $80-85 \%$ of renewable resources and drying can proceed despite the limited unsaturations' concentration (the iodine value of olive oil is only 85 versus $>140$ for typical drying oil such as linseed oil). However, the flexibility of the S-C bond together with the limited cross-linking density have resulted in poor network mechanical integrity. Photopolymerization was triggered with a conventional medium-pressure $\mathrm{Hg}$ lamp in presence of three different thiol cross-linkers (T1-3) and a radical photoinitiator (all structures are shown in Scheme 2). Cross-linking can proceed in principle by two 
concomitant mechanisms: photo-oxidation and thiol-ene photopolymerization, whose relative importance must be established. In this study, real-time Fourier transform infrared spectroscopy (RT-FTIR) has been mainly used to assess the reactivity of the olive oil/polythiol mixture using linseed oil as reference system.

\section{Materials and Methods}

\subsection{Materials}

2,2'-(ethylenedioxy)diethanethiol $95 \quad \% \quad$ (T1), hexanedithiol $99.5 \quad \% \quad$ (T2), trimethylolpropanetris(3-mercaptopropionate) $95 \%$ (T3), 2-hydroxy 2-methylpropiophenone 97\% (also called Darocure 1173, radical photoinitiator) were purchased from Sigma-Aldrich. Byk 333 is a poly (ethylene oxide)-polydimethylsiloxane copolymer used as a wetting agent (BykChemie). The refined pomace olive oil and lampante olive oil were purchased from a local commercial refining oil factory located at Agareb in Sfax (Tunisia) in Sept. 2014. Linseed oil was purchased from Sigma-Aldrich. All chemicals were used as received without further purification. Need comments on the different methods to characterize the native oils

\subsection{Thiol-ene photopolymerization of olive oil/polythiol films}

For a mixture containing a stoichiometric thiol-ene ratio, $1 \mathrm{~g}$ of pomace or lampante olive oil was mixed with $0.3 \mathrm{~g}$ of ethylene glycol dithiol (T1), $0.42 \mathrm{~g}$ of trimethylolpropanetris (3mercaptopropionate) (T2) and $0.24 \mathrm{~g}$ of hexanedithiol (T3) with $1 \%$ of radical photoinitiator D1173 and $0.1 \%$ of wetting agent. Under sub-stoichiometric conditions (thiol/ene: 1/1.45), 1 $\mathrm{g}$ of pomace or lampante olive-oil was mixed with $0.2 \mathrm{~g}$ of T1, $0.3 \mathrm{~g}$ of $\mathbf{T 2}$, and $0.16 \mathrm{~g}$ of $\mathbf{T 3}$ without photoinitiator and the same formulations was prepared again with $1 \mathrm{wt} \%$ of photoinitiator D1173. Additionally, quantities were adjusted to have the same thiol-ene molar ratio when using linseed oil exhibiting a higher content of unsaturations. In addition, oxophotopolymerization was performed without thiol derivatives, with the additional presence of photoinitiator in certain experiments.

All the irradiation experiments were performed at ambient temperature in the presence of air. A liquid thiol-ene monomer film ( $6 \mu \mathrm{m}$ thick) was applied onto a borosilicate glass plate by means of a calibrated wire-wound applicator without dewetting problems through the use of Byk-333. Two UV irradiation devices were implemented. First, the liquid films were exposed to the polychromatic light of a medium pressure mercury-xenon arc lamp (Hamamatsu L8252, equipped with a reflector at $365 \mathrm{~nm})\left(\lambda: 250-600 \mathrm{~nm}\right.$, irradiance $\left.=\mathrm{I}=685 \mathrm{~mW} \mathrm{~cm}{ }^{-2}\right)$ 
focalized vertically on the sample through a flexible light guide placed at a distance of $3 \mathrm{~cm}$ from the film. The irradiation device was also equipped with an elliptical reflector $(365 \mathrm{~nm})$ that efficiently reflects the UV light, and lets heat rays pass through, preventing any significant increase of temperature. This cold reflector cuts off heat so that the local temperature increases of only ca. $3{ }^{\circ} \mathrm{C}$ during a typical photopolymerization experiment. With this lamp, the photopolymerization kinetics were monitored in situ by real-time Fourier transform infrared spectroscopy (see characterization section). Additionally, UV exposure was carried out through ten successive passes under a UV conveyor (Qurtech) equipped with an H-bulb lamp (Fusion). The belt speed of the conveyor was set to $10 \mathrm{~m} \mathrm{~min}^{-1}$. Under these conditions, the emitted light dose for each pass is $1.35 \mathrm{~J} \mathrm{~cm}^{-2} \mathrm{UV}_{\mathrm{A}}[320-390 \mathrm{~nm}]: 0.46 \mathrm{Jcm}^{-2}$, $\mathrm{UV}_{\mathrm{B}}$ [280-320 nm]: $0.31 \mathrm{~J} \mathrm{~cm}^{-2}, \mathrm{UV}_{\mathrm{C}}$ [250-260 nm]: $0.08 \mathrm{~J} \mathrm{~cm}^{-2}$ and $\mathrm{UV}_{\mathrm{V}}$ [395-445 nm]: 0.50 $\mathrm{J} \mathrm{cm}^{-2}$ ) and corresponds to an exposure time of $0.23 \mathrm{~s}$.

\subsection{Characterization}

Real-time Fourier transform infrared (RT-FTIR) spectra were obtained with a Bruker Vertex 70 spectrophotometer equipped with a liquid nitrogen cooled mercury-cadmium-telluride (MCT) detector working in the rapid scan mode. The resolution of the spectra was $4 \mathrm{~cm}^{-1}$ with an average of 4 scans $\mathrm{s}^{-1}$. The conversion kinetics were monitored online by measuring the decay of the IR absorption bands at $2860 \mathrm{~cm}^{-1}$ (SH stretching) and $3010 \mathrm{~cm}^{-1}$ (olefinic $\mathrm{CH}$ stretch) under simultaneous exposure to UV light. Differential scanning calorimetry (DSC) was carried out on a TA Q2000 DSC using a heat-cool-heat thermal cycle. $5 \mathrm{mg}$ of poly(disulfide) film was placed in an hermetic aluminum pan. The first cycle started by heating the sample from -90 to $100{ }^{\circ} \mathrm{C}$ at $10{ }^{\circ} \mathrm{C} \mathrm{min}-1$. The second cycle cooled the sample back to $-90{ }^{\circ} \mathrm{C}$. The third step heated the sample again from -90 to $100{ }^{\circ} \mathrm{C}$ at $10{ }^{\circ} \mathrm{C} \mathrm{min}{ }^{-1}$.

\section{Results and discussion}

Table 1 shows a precise comparison of the composition of lampante and pomace olive oils with a conventional virgin olive oil in terms of acidity, peroxide value, polycyclic aromatic hydrocarbon composition and fatty acidy content. As expected, lampante olive oil has a much 
higher acidity, and peroxide value making it unsuitable to human consumption. Pomace olive oil is characterized by a much lower concentration in polyphenol and tocopherol because it has been refined. However, all olive oils show very slight differences in the proportion of fatty acids with a majority of oleic acid (C18:1, 62-64 \%) and linoleic acid (C18:2, 18-20 \%).

\subsection{Investigation of $\mathbf{U V}$-assisted oxopolymerization}

Prior to incorporate thiols cross-linkers, the ability of pomace and lampante olive oils to selfpolymerize by a photo-assisted auto-oxidation process was explored. Without the addition of catalyst, several authors pointed out that UV irradiation can accelerate the oxidation rate. To provide consistent basis of comparison, linseed oil was also used. Due to its high concentration of unsaturations, this drying oil is known to be sensitive to auto-oxidation, and has been used for decades as painting and linoleum though its capacity to form a optically transparent film [26].

Before irradiation, the high frequency transmission IR spectra of linseed oil and pomace olive oil, in Figure 1, are somehow similar. They show the presence of five distinct peaks. Four are straightforwardly assigned to $\mathrm{CH}$ stretching vibration from aliphatic groups at 2854, 2872, 2917 and $2954 \mathrm{~cm}^{-1}$ which are attributed to $\mathrm{CH}_{2}$ symmetric, $\mathrm{CH}_{3}$ symmetric, $\mathrm{CH}_{2}$ antisymmetric and $\mathrm{CH}_{3}$ antisymmetric vibrations, respectively. The singlet at $3007 \mathrm{~cm}^{-1}$ is indicative of olefinic carbon-hydrogen $(=\mathrm{C}-\mathrm{H})$ stretching vibration in hydrocarbon chain. The position of this $\mathrm{CH}$ mode peak supports the presence of internal olefin groups with a cis conformation. Its higher intensity for linseed oils indicates a higher concentration of unsaturation as expected. Note that the spectrum of lampante olive oil is similar to that of pomace olive oil, and has not been represented in Figure 1. After UV exposure (250 -600 nm, $685 \mathrm{~mW} \mathrm{~cm}^{-2}$ ) during $60 \mathrm{~min}$, only this latter band has evolved, and has completely vanished below the noise level. This result is in agreement with a UV-assisted oxopolymerization mechanism involving, among other, various addition reactions of oxidation product radicals onto internal olefins as detailed below. The well-established photo-induced auto-oxidation mechanism has been fully commented on Figure 2 [25]. Real-time FTIR spectroscopy enabled to monitor the conversion rates of $\mathrm{C}=\mathrm{C}$ bonds during time. Consequently, the kinetic curve of Figure 3 reflects only one mode of cross-linking by radical addition onto olefins (eq 5 and 8 in Figure 3), while the other cross-linking reactions (eq 9) are difficult to assess by FTIR spectroscopy. Despite a higher number of reactive sites, the conversion-time curves of 
linseed oils, in Figure 3, shows a higher reactivity since a full conversion can be reached within 10 min whereas 60 min are necessary for pomace or lampante olive oils. Regardless of the oil, all films remain sticky after UV treatment. The tackiness is more pronounced with the two olive oils probably due to the lower concentration of unsaturations yielding a lower crosslinking density. The higher concentration in linoleate (15\%) and linolenate (57\%) segments in linseed oils compared to olive oil (19\% and <1\%, respectively) accounts for its higher reactivity compared to the olive oils (see detailed composition in Table 1).

Figure 4 shows the conversion-time curves for the three oils in presence of conventional $\alpha$ cleavable radical photo initiator (2,2-dimethyl-2-hydroxyacetophenone, 1 wt $\%$ ) conventionally used to trigger free radical photopolymerization. Under these conditions, oxidation initiation does no longer result from impurities (eq 1) but from benzoyl and alkyl radicals produced by the photolysis of the aromatic ketone species (Norrish type I reaction). With a higher concentration of radicals in the medium, the conversion profiles become almost similar regardless of the type of oils. Full disappearance of $\mathrm{C}=\mathrm{C}$ is accomplished in less than $10 \mathrm{~min}$. Nevertheless, all the coatings remain sticky after irradiation although the quality of the film has been improved. This result can be related to the ability of both benzoyl and alkyl radical initiators to readily attack the $\pi$-bond of carbon-carbon double bond of unsaturated oils. However, as observed for most 1,2-disubstituted ethylene monomers, the approach of the resultant propagating radical to a new $\mathrm{C}=\mathrm{C}$ is sterically hindered because of the $\beta$ substituents, and therefore, propagation of polymerization is not possible (there is also a thermodynamic factor that superimposes to this kinetic factor) [26]. This first study shows the applicability of a UV-driven photo-oxidation process for low-grade olive oils proceeding in a matter of minutes with a radical photoinitiator. To achieve subsequently dry films, we have attempted to combine photo-oxidation with thiol-ene photopolymerization

\subsection{Investigation of UV-driven thiol-ene photopolymerization}

\subsubsection{Photopolymerization with dithiol T1.}

In this new series of experiments, a 2,2'-(ethylenedioxy)diethanethiol(T1) / oil mixture was prepared to obtain a thiol:ene molar ratio of 1 for the three types of oil (linseed, pomace and lampante olive oils). Irradiation was performed in presence of $1 \mathrm{wt} \%$ radical photointiator. As the internal alkenes are less reactive, they will tend to cause the propagation reaction to be 
slow and rate limiting compared to chain transfer which involves a dithiol exhibiting readily abstractable hydrogen atoms. Scheme 3 depicts the idealized cross-linked thioether structure after thiol-ene photopolymerization.

In Figure 5, the high frequency region of the FTIR spectra shows five peaks assigned to $\mathrm{CH}$ stretching vibrations as seen previously, as well as a weakly intense single band at $2564 \mathrm{~cm}^{-1}$ attributed to the S-H stretching mode. Its distinctive presence establishes the nonvolatile character of the dithiol compound T1. Whatever the type of oil, there is a fast and concomitant decrease of this feature with maximum at $2564 \mathrm{~cm}^{-1}$ and the $v(=\mathrm{C}-\mathrm{H})$ stretching vibration at $3007 \mathrm{~cm}^{-1}$ within only $30 \mathrm{~s}$. All the three films are dry and rubbery after $1 \mathrm{~min} 30$ $\mathrm{s}$ of irradiation.

The kinetic treatment by rapid scan FTIR analysis allows to distinguish the respective conversions of $\mathrm{C}=\mathrm{C}$ and $\mathrm{SH}$ functions, as shown in Figure 6. The sample based on pomace olive oils copolymerizes faster than that based on linseed oil. Full conversion of $\mathrm{C}=\mathrm{C}$ is achieved within $10 \mathrm{~s}$ while more than twice is necessary with the latter. This result may be related to the higher concentration in unsaturations of linseed oil. In both systems, there is a discrepancy between the thiols and carbon-carbon double bonds conversions which are fully converted at a higher rate. This result can be interpreted on the basis of a dual thiol-ene and photo-oxidation mechanism of photopolymerization for the $\mathrm{C}=\mathrm{C}$ bonds. As a part of the olefins are consumed by oxopolymerization, they are not available for thiyl addition (present in stoichiometric amount). The larger gap in conversion rates in the case of linseed oil may translate a higher tendency for auto-oxidation because of the lability of the doubly allylic methylenes. The thiol-ene reactivity of triglycerides is ruled by two opposite effects: the steric hindrance of the reactive 1,2-disubstituted ethylene groups which tends to slowdown the addition; and conversely the electron-donating inductive effect of the two surrounded alkylene substituents which enhances the reactivity. Very important for linseed oil is that bis-allylic $\mathrm{H}$ abstraction (via auto-oxidation mechanism) can generate conjugated alkenes which are known to copolymerize very slowly with thiols, presumably because of the stability of the carboncentered allylic radical formed upon the addition of the thiyl radical to the carbon-carbon double bond. This can contribute to slower reactivity of linseed oil. In both cases the conversion rates remain high in the order of seconds versus minutes for auto-oxidation, suggesting that a majority of alkenes are actually involved into a thiol-ene coupling process. A comment may be added about thiol consumption that has been pursued despite the absence of alkene. UV light $(\lambda<300 \mathrm{~nm})$ can promote thiol photolysis yielding thiyl radicals which 
can dimerize into disulfide bonds by bimolecular recombination [27]. Finally, there is no difference in the kinetic behavior of pomace and lampante oils despite the fact that pomace contain a much higher concentration in polyaromatic species which may inhibit the radical polymerization.

\subsubsection{Influence of various experimental parameters.}

The influence of photoinitiator, nature of polythiol, thiol-ene molar ratio, film thickness and UV lamp are gathered in Table 2. Only the results of pomace olive oil (runs a) and linseed oil (runs b) are summarized since similar results were obtained with lampante olive oil.

One of the salient feature of thiol-ene photopolymerization is that for UV irradiation, no added photoinitiator molecules are required to initiate the polymerization [28]. As the $\mathrm{Hg}$ medium pressure light is not filtered, a portion of light is emitted $<300 \mathrm{~nm}$ which is particular relevant for hydrogen abstraction of thiol. Compared to the reference experiment with photoinitiator (run $\mathbf{a}$ and $\mathbf{b}$ ), the self-initiation is effective and a full conversion of $\mathrm{SH}$ and $\mathrm{C}=\mathrm{C}$ is achieved despite slower polymerization rates for pomace olive oil (run a1) and linseed oil (run b1). The results show that films obtained by the formulations with photoinitiator exhibit better performance than those obtained without photoinitiator. Pomace olive oil was also copolymerized with two other polythiol of functionality 2 (T2: hexanedithiol, run a2) and 3 (T3: trimethylolpropanetris(3-mercaptopropionate), run a3). A higher reactivity was found with these novel thiols, but the resultant film was found to be sticky. This contradictory result was assigned to a partial miscibility of the thiol with the oil. In addition, increasing the thickness has a limited impact on reaction rates and final conversion (runs a4 and a5).

Production of films was also up-scaled using a UV-conveyor (whose technical characteristics are detailed in the method section) to perform thermos-mechaninal analysis. After 4 passes in the UV conveyor, dry films were produced based on pomace and lampante olive oils. DSC analysis of run a revealed a glass transition arising at $-42{ }^{\circ} \mathrm{C}$ (Figure S1 of Supporting Information SI). Such value is consistent with that of conventional poly(thioether) network materials formed by thiol-ene step-growth polymerization [29]. Though solid materials were achieved in all instances, the resultant films obtained from the two olive oils showed very poor mechanical properties that we have attributed to three factors: the inherent flexibility of thioether linkage, the long hydrocarbon groups of fatty acids, and the low cross-linking density due to the limited concentration of unsaturations in olive oils. Consequently, the determination of relevant mechanical quantities including hardness, elastic modulus, residual 
stress, or coating fracture toughness - normally accessible by indentation testing or scratching - has turned out to be impossible or inappropriate. This aspect is common to many low transition temperature poly(thiother) networks which are elastomeric and possess poor mechanical integrity at and above $25^{\circ} \mathrm{C}$ [30]. Works are underway to involve high glass transition resins, polystyrene or poly(methyl methacrylate for example, to increase modulus and improve the toughness and mechanical stress of the films [31].

\section{Conclusions}

This study provides evidence that solid cross-linked transparent coatings can be produced from two low grade olive oils (pomace and lampante) by a tandem UV process combining essentially thiol-ene photopolymerization, and in a very minor extent auto-oxidation process. 2,2'-(ethylenedioxy)diethanethiol has proven to be an appropriate dithiol for reactivity and miscibility reasons. Using a $\mathrm{Hg}$-Xe medium-pressure $\mathrm{Hg}$ arc, almost full conversion of thiol and $\mathrm{C}=\mathrm{C}$ are achieved in less than 20 seconds. Under an industrial UV-conveyor large films of a few tenths $\mathrm{cm}^{2}$ were also obtained after only 4 passes. While this study demonstrates conclusively the possibility to form poly(thioether) cross-linked films from low grade olive oils, improvements are required to enhance network mechanuical integrity. One means of improvement would to prepare a biphasic material based on a soft thiol-ene thermoset and a hard thermoplastic.

\section{Acknowledgements}

This research was financed by Ministry of Higher Education and Scientific Research (Tunisia) under reference "UR11/ES74".

\section{Conflict of interest}

We declare no conflicts of interest. 


\section{References}

1. Fouassier, J. P., Lalevée, J., Photoinitiators for Polymer Synthesis: Scope, Reactivy and Efficiency. Wiley-VCH: Weinheim, Germany, 2012.

2. Schwalm, R., UV Coatings Basics, Recent Developments and New Applications. First ed.; Elsevier: Amsterdam, The Netherlands, 2007; p 223.

3. Sharma, V., Kundu, P. P., Addition polymers from natural oils - A review. Prog. Polym. Sci. 2006, 31, 983-1008.

4. Meier, M. A. R., Metzger, J. O., Schubert, U. S., Plant oil renewable resources as green alternatives in polymer science. Chem. Soc. Rev. 2007, 36, 1788-1802.

5. de Espinosa, L. M., Meier, M. A. R., Plant oils: The perfect renewable resource for polymer science?! Eur. Polym. J. 2011, 47, 837-852.

6. Sharmin, E., Zafar, F., Akram, D., Alam, M., Ahmad, S., Recent advances in vegetable oils based environment friendly coatings: A review. Ind. Crops Prod. 2015, 76, 215-229.

7. Gandini, A., Lacerda, T. M., Carvalho, A. J. F., Trovatti, E., Progress of Polymers from Renewable Resources: Furans, Vegetable Oils, and Polysaccharides. Chem. Rev. 2016, 116, $1637-$ 1669.

8. Gandini, A., Lacerda, T. M., Polymers from Plant Oils. Smithers-Rapra: Shawbury, UK, 2015; p 180.

9. Gan, Y., Jiang, X., CHAPTER 1 : Photo-cured Materials from Vegetable Oils. In Green Materials from Plant Oils, Liu, Z.; Kraus, G., Eds. RSC: Cambridge, UK, 2014; pp 1-27.

10. Zou, K. R., Soucek, M. D., UV-curable cycloaliphatic epoxide based on modified linseed oil: Synthesis, characterization and kinetics. Macromol. Chem. Phys. 2005, 206, 967-975.

11. Zovi, O., Lecamp, L., Loutelier-Bourhis, C., Lange, C. M., Bunel, C., A solventless synthesis process of new UV-curable materials based on linseed oil. Green Chem. 2011, 13, 1014-1022.

12. Fertier, L., Koleilat, H., Stemmelen, M., Giani, O., Joly-Duhamel, C., Lapinte, V., Robin, J. J., The use of renewable feedstock in UV-curable materials - A new age for polymers and green chemistry. Prog. Polym. Sci. 2013, 38, 932-962.

13. Ye, G., Courtecuisse, F., Allonas, X., Ley, C., Croutxe-Barghorn, C., Raja, P., Taylor, P., Bescond, G., Photoassisted oxypolymerization of alkyd resins: Kinetics and mechanisms. Prog. Org. Coat. 2012, 73, 366-373.

14. Klaasen, R. P., van der Leeuw, R. P. C., Fast drying cobalt-free high solids alkyd paints. Prog. Org. Coat. 2006, 55, 149-153.

15. Samuelsson, J., Jonsson, M., Brinck, T., Johansson, M., Thiol-ene coupling reaction of fatty acid monomers. J. Polym. Sci. Polym. Chem. 2004, 42, 6346-6352.

16. Palaskar, D. V., Boyer, A., Cloutet, E., Le Meins, J. F., Gadenne, B., Alfos, C., Farcet, C., Cramail, H., Original diols from sunflower and ricin oils: Synthesis, characterization, and use as polyurethane building blocks. J. Polym. Sci. Polym. Chem. 2012, 50, 1766-1782.

17. Turunc, O., Meier, M. A. R., The thiol-ene (click) reaction for the synthesis of plant oil derived polymers. Eur. J. Lipid Sci. Techno. 2013, 115, 41-54.

18. Bexell, U., Berger, R., Olsson, M., Grehk, T. M., Sundell, P. E., Johansson, M., Bonding of vegetable oils to mercapto silane treated metal surfaces: Surface engineering on the nano scale. Thin Solid Films 2006, 515, 838-841.

19. Black, M., Rawlins, J. W., Thiol-ene UV-curable coatings using vegetable oil macromonomers. Eur. Polym. J. 2009, 45, 1433-1441.

20. Hoyle, C. E., Bowman, C. N., Thiol-Ene Click Chemistry. Angewandte Chemie-International Edition 2010, 49, 1540-1573. 
21. Luo, A. F., Jiang, X. S., Lin, H., Yin, J., "Thiol-ene" photo-cured hybrid materials based on POSS and renewable vegetable oil. J. Mater. Chem. 2011, 21, 12753-12760.

22. Echeverri, D. A., Cadiz, V., Ronda, J. C., Rios, L. A., Synthesis of elastomeric networks from maleated soybean-oil glycerides by thiol-ene coupling. Eur. Polym. J. 2012, 48, 2040-2049.

23. Denes, F., Pichowicz, M., Povie, G., Renaud, P., Thiyl Radicals in Organic Synthesis. Chem. Rev. 2014, 114, 2587-2693.

24. Yucel, Y., Optimization of biocatalytic biodiesel production from pomace oil using response surface methodology. Fuel Proc. Techno. 2012, 99, 97-102.

25. Soucek, M. D., Khattab, T., Wu, J., Review of autoxidation and driers. Prog. Org. Coat. 2012, 73, 435-454.

26. Claudino, M., Johansson, M., Jonsson, M., Thiol-ene coupling of 1,2-disubstituted alkene monomers: The kinetic effect of cis/trans-isomer structures. Eur. Polym. J. 2010, 46, 2321-2332.

27. Feillee, N., De Fina, M., Ponche, A., Vaulot, C., Rigolet, S., Jacomine, L., Majjad, H., Ley, C., Chemtob, A., Step-growth thiol-thiol photopolymerization as radiation curing technology. J. Polym. Sci.: Polym. Chem. 2017, 55, 117-128.

28. Hoyle, C. E., Lowe, A. B., Bowman, C. N., Thiol-click chemistry: a multifaceted toolbox for small molecule and polymer synthesis. Chem. Soc. Rev. 2010, 39, 1355-1387.

29. McNair, O. D., Janisse, A. P., Krzeminski, D. E., Brent, D. E., Gould, T. E., Rawlins, J. W., Savin, D. A., Impact Properties of Thiol-Ene Networks. ACS Appl. Mater. Interfaces 2013, 5, 1100411013.

30. Kasprzak, S. E., Martin, B., Raj, T., Gall, K., Synthesis and thermomechanical behavior of (qua)ternary thiol-ene(/acrylate) copolymers. Polymer 2009, 50, 5549-5558.

31. Hearon, K., Nash, L. D., Rodriguez, J. N., Lonnecker, A. T., Raymond, J. E., Wilson, T. S., Wooley, K. L., Maitland, D. J., A High-Performance Recycling Solution for Polystyrene Achieved by the Synthesis of Renewable Poly(thioether) Networks Derived from d-Limonene. Adv. Mater. 2014, $26,1552-1558$.

32. Rabek, J. F., Polymer Photodegradation: Mechanisms and experimental methods. Chapman Hall: London (UK), 1994.

33. Verdu, J., Vieillissement oxydant des polymères aspects cinétiques. Lavoisier: Cachan, France, 2012. 
Table

Table 1.

\begin{tabular}{|c|c|c|c|}
\hline & Virgin olive oil & Lampante olive oil & Pomace olive oil \\
\hline Acidity (\%) & 0.45 & 4.75 & 0.12 \\
\hline Peroxide value (meq $\mathrm{O}_{2} \backslash \mathrm{kg}$ ) & 6.35 & 24.5 & 14.03 \\
\hline $\mathrm{K} 232$ (Absorbance at $232 \mathrm{~nm}$ ) & 2.28 & 3.18 & 3.105 \\
\hline $\mathrm{K} 270$ (Absorbance at $270 \mathrm{~nm}$ ) & 0.22 & 0.385 & 0.853 \\
\hline Polyphenol (ppm) & 716.07 & 485.36 & 130.35 \\
\hline Tocopherol (ppm) & 850.35 & 547.32 & 350.24 \\
\hline Carotene (ppm) & 15.55 & 8.25 & 2.85 \\
\hline Chlorophyll (ppm) & 9.89 & 1.27 & 6.85 \\
\hline C16:0 & 15.02 & 14.34 & 13.75 \\
\hline C16:1 & 0.79 & 0.90 & 0.87 \\
\hline C18:0 & 1.80 & 1.99 & 1.77 \\
\hline C18:1 & 63.09 & 63.72 & 62.77 \\
\hline C18:2 & 18.08 & 17.86 & 19.53 \\
\hline C18:3 & 0.71 & 0.85 & 0.78 \\
\hline C20:0 & 0.25 & 0.20 & 0.26 \\
\hline C20:1 & 0.19 & 0.12 & 0.20 \\
\hline
\end{tabular}


Table 2. Comparison of conversion rate between olive pomace oil and linseed oil

\begin{tabular}{|c|c|c|c|c|c|c|c|c|}
\hline \multirow[t]{2}{*}{ Run } & \multirow[t]{2}{*}{ Oil } & \multirow[t]{2}{*}{ Thiol } & \multirow[t]{2}{*}{ PI } & \multirow[t]{2}{*}{ Thickness $(\mu \mathrm{m})$} & \multicolumn{2}{|c|}{ Conversion after $5 \mathrm{~s}$} & \multicolumn{2}{|c|}{ Conversion after 90s } \\
\hline & & & & & $\mathrm{C}=\mathrm{C}$ & S-H & $\mathrm{C}=\mathrm{C}$ & S-H \\
\hline $\mathbf{A}$ & pomace olive & T1 & Yes & 6 & 100 & 70 & 100 & 100 \\
\hline a1 & pomace olive & $\mathrm{T} 1$ & No & 6 & 25 & 10 & 100 & 100 \\
\hline $\mathbf{a} 2$ & pomace olive & $\mathrm{T} 2$ & Yes & 6 & 60 & 40 & 100 & 100 \\
\hline $\mathbf{a 3}$ & pomace olive & $\mathrm{T} 3$ & Yes & 6 & 100 & 65 & 100 & 100 \\
\hline a4 & pomace olive & $\mathrm{T} 1$ & Yes & 10 & 100 & 70 & 100 & 100 \\
\hline a5 & pomace olive & $\mathrm{T} 1$ & Yes & 4 & 100 & 70 & 100 & 100 \\
\hline a6 & $\begin{array}{l}\text { pomace olive } \\
\text { (non- } \\
\text { stoichiometric) }\end{array}$ & $\mathrm{T} 1$ & Yes & 6 & 90 & 60 & 100 & 100 \\
\hline B & linseed & $\mathbf{T 1}$ & Yes & 6 & 80 & 40 & 100 & 100 \\
\hline b1 & linseed & $\mathrm{T} 1$ & No & 6 & 75 & - & 100 & 100 \\
\hline
\end{tabular}




\section{Scheme captions}

Scheme 1. Example of triglyceride chain containing three fatty acid chains joined by a glycerol center found in pomace and lampante olive oil. The approximate fatty acid contents of these oils and that of linseed oil is given in the table below.

Scheme 2. Chemical structures of the three polythiol cross-linkers

Scheme 3. Polythioether network structure resulting from the reaction of a dithiol with a nonmodified unsaturated triglyceride 


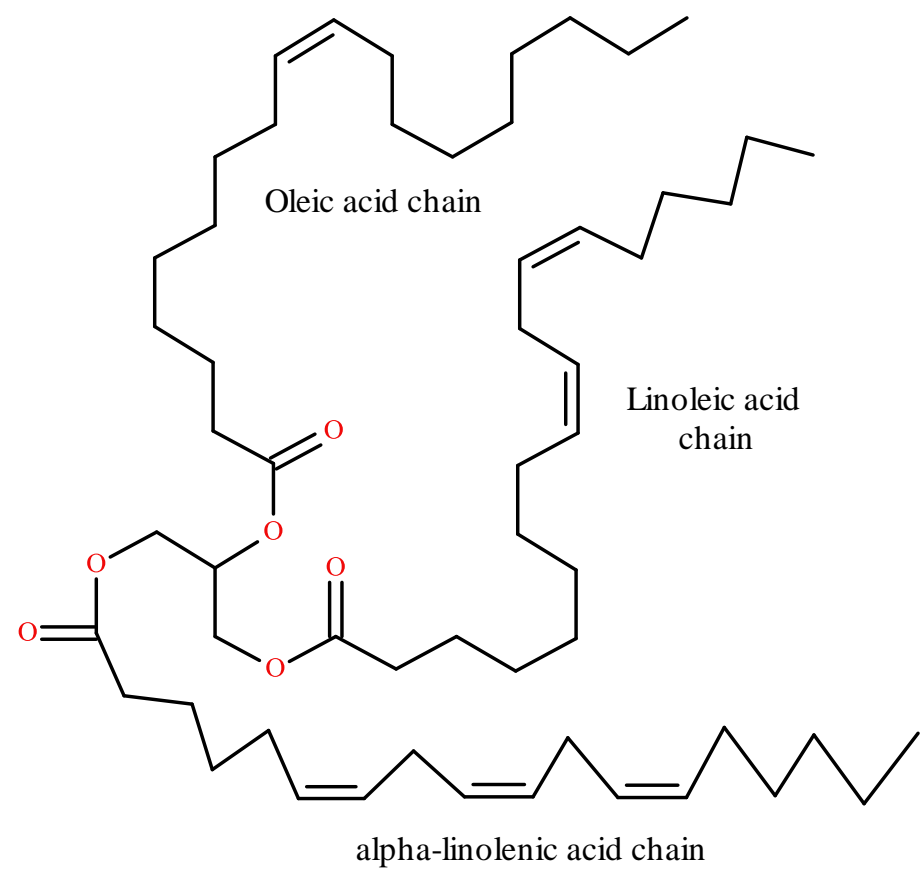

\begin{tabular}{|lllll|}
\hline Oil & $\begin{array}{l}\text { Saturated } \\
\text { fatty acids } \\
10 \%\end{array}$ & $\begin{array}{l}\text { Oleic Acid } \\
\text { (C18:1) } \\
18 \%\end{array}$ & $\begin{array}{l}\text { Linoleic } \\
\text { Acid (C18:2) } \\
15 \%\end{array}$ & $\begin{array}{l}\boldsymbol{\alpha} \text {-Linolenic } \\
\text { Acid (C18:3) } \\
57 \%\end{array}$ \\
$\begin{array}{l}\text { Linseed oil } \\
\begin{array}{l}\text { Olive-oil } \\
\text { (lampante, } \\
\text { pomace or } \\
\text { virgin) }\end{array}\end{array}$ & $15-17 \%$ & $62-64 \%$ & $18-20 \%$ & $<1 \%$ \\
\hline
\end{tabular}

\section{Scheme 1}


HS<smiles>CCCOCCOCCS</smiles>

T1: Ethylene Glycol Dithiol<smiles>CCC(COC(=O)CCS)(COC(=O)CCS)COC(=O)CCS</smiles>

T2: Trimethylolpropane tris(3-mercaptopropionate)<smiles>SCCCCCCS</smiles>

T3: Hexanedithiol

Scheme 2 


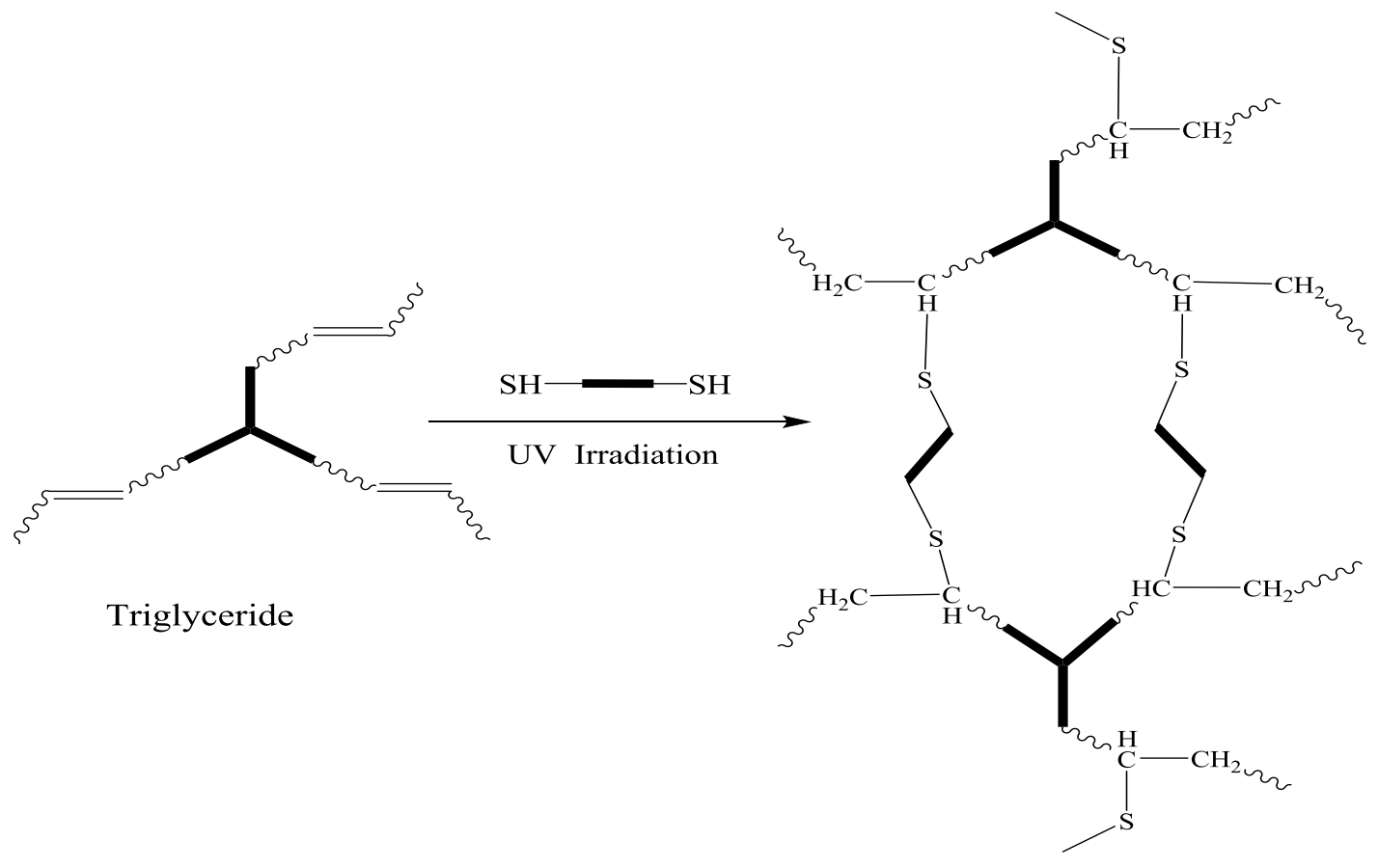

Scheme 3 


\section{Figures caption}

Figure 1. Effect of UV irradiation ( $\mathrm{Hg}$-Xe lamp, $60 \mathrm{~min}$ ) on the transmission infrared spectra of pomace olive oil (a) and linseed oil (b) films. The vertical lines indicate the locations of IR bands in the 2750-3050 region assigned to $\mathrm{CH}$ stretching modes.

Figure 2. Conversion profiles of $\mathrm{C}=\mathrm{C}$ bonds of the three oil samples during $\mathrm{UV}$ irradiation $(\mathrm{Hg}-\mathrm{Xe}, 60 \mathrm{~min}$ ) as measured by RT-FTIR (integration of the olefinic $=\mathrm{C}-\mathrm{H}$ stretching band at $3007 \mathrm{~cm}^{-1}$ ).

Figure 3. Light absorbing impurities $(\mathbf{R H})$ can produce radicals $(\mathrm{R} \bullet)$ in the presence of air (oxygen) under UV-visible irradiation (eq 1), even in absence of any compound containing intra-molecular chromophoric groups [32]. The second step is the formation of alkyl radicals $\left(\mathbf{P}^{*}\right)$ by hydrogen abstraction on unsaturated fatty acid chain of plant oils (PH). The key reaction in the propagation sequence is the formation of peroxy radicals (POO•) by the reaction of alkyl radicals $(\mathrm{P} \bullet$ ) with oxygen (eq 3). The two next propagation steps involving the peroxy radicals are hydrogen abstraction to generate a new alkyl radical (P•) (eq 4) and the addition onto carbon double bonds (eq 5). The efficiency of this couple of reaction (eq 4 and 5) is strongly dependent on the photolysis of hydroperoxide species which exhibits a low extinction coefficient in the UV range $\left(1 \mathrm{~L} \mathrm{~mol}^{-1} \mathrm{~cm}^{-1}\right.$ at $300 \mathrm{~nm}$ but a quantum yield of 1) [33]. The decomposition of oxidation products generates alkoxy radicals (PO) and hydroxyl radicals $\left(\mathrm{OH}^{\circ}\right)$ (eq 6). These two oxygen reactive species are much more reactive than peroxy radicals and can be also involved in hydrogen abstraction (eq 7) on double bond addition (eq 8). In addition to reactions 5 and 8, cross-linking can proceed through a number of termination reactions via bimolecular recombination of various radicals (eq 9).

Figure 4. Conversion-time curves during the photooxidation of three oils in presence of 1 wt\% 2,2-dimethyl-2-hydroxyacetophenone (radical photoinitiator).

Figure 5. Temporal evolution of FTIR spectra of T1/oil film during UV irradiation ( $\mathrm{Hg}-\mathrm{Xe}$ lamp) in presence of radical PI.

Figure 6. Conversion profiles $(\mathrm{C}=\mathrm{C}$ and $\mathrm{SH})$ of two oil/ $\mathrm{T}_{\mathrm{i}}$ films under $\mathrm{UV}$ irradiation $(\mathrm{Hg}-\mathrm{Xe}$ lamp, $1 \mathrm{~min} 20 \mathrm{~s}$ ). 


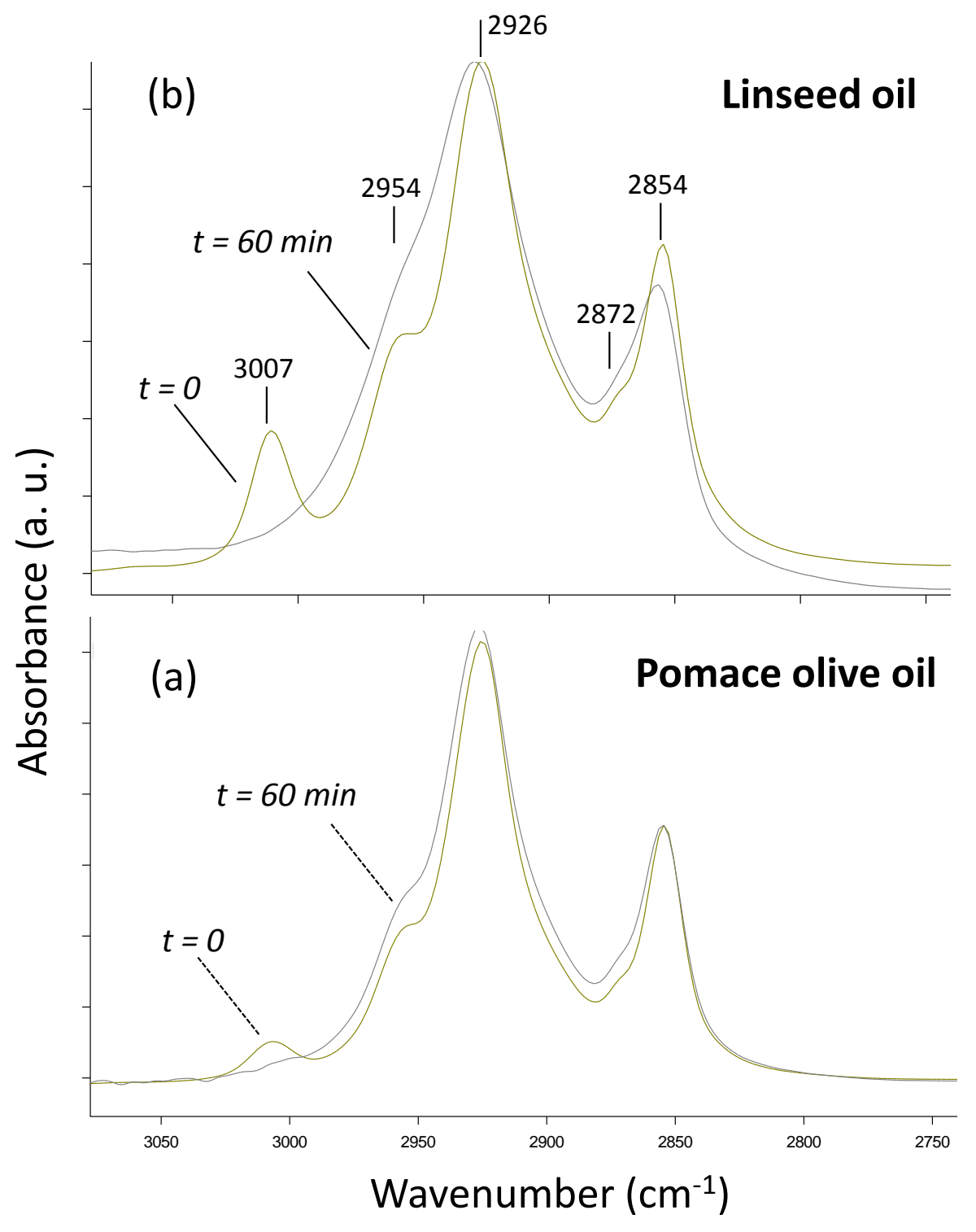

Figure 1 


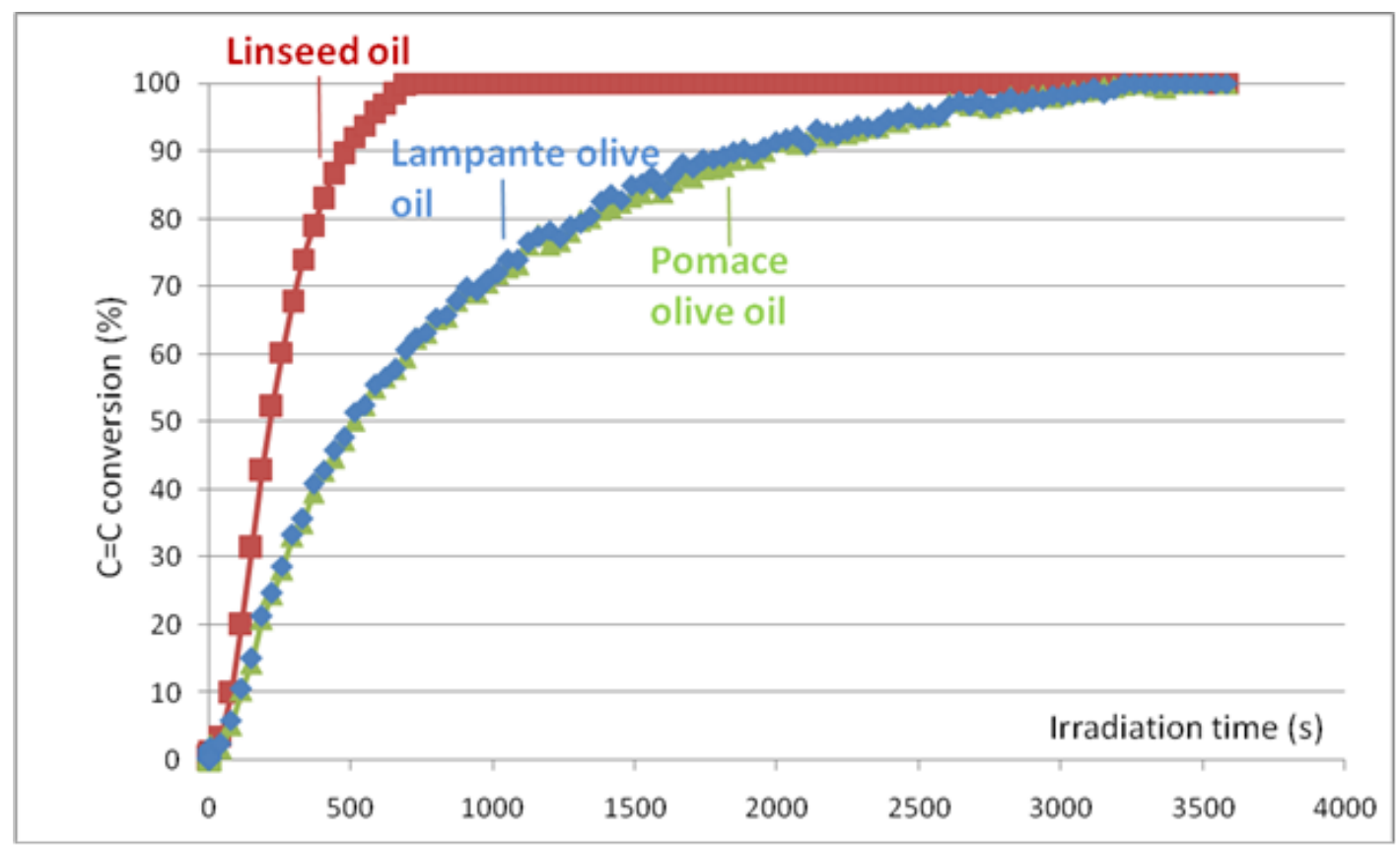

Figure 2 
Initiation step

$\mathrm{RH} \rightarrow \mathrm{R}^{\bullet}+\mathrm{H}_{2} \mathrm{O}^{\bullet}$ (under UV light and $\mathrm{O}_{2}$ )

$\mathrm{R}^{\bullet}+\mathrm{PH} \rightarrow \mathrm{P}^{\bullet}+\mathrm{RH}$

Propagation sequence

$\mathrm{P}^{\bullet}+\mathrm{O}_{2} \rightarrow \mathrm{POO}^{\circ}$

$\mathrm{POO}^{\circ}+\mathrm{PH} \rightarrow \mathrm{P}^{\bullet}+\mathrm{POOH}$

$\mathrm{POO}^{\circ}+-\mathrm{CH}=\mathrm{CH}-\rightarrow$ POO-CH-CH${ }^{\circ}-$

Photolysis of hydroperoxide species

$\mathrm{POOH} \rightarrow \mathrm{PO}^{\circ}+{ }^{\circ} \mathrm{OH}$ (under UV light)

Reactions involving peroxy radicals

$\mathrm{PO}^{\bullet}+\mathrm{PH} \rightarrow \mathrm{P}^{\bullet}+\mathrm{POH}$

$\mathrm{PO}^{\circ}+-\mathrm{CH}=\mathrm{CH}-\rightarrow \mathrm{PO}-\mathrm{CH}-\mathrm{CH}^{\circ}-$

Termination reactions via bimolecular recombination $\mathrm{PO} \% \mathrm{POO} / \mathrm{PO} \rightarrow \mathrm{P}-\mathrm{P} / \mathrm{POP} / \mathrm{POOP}$

Figure 3 


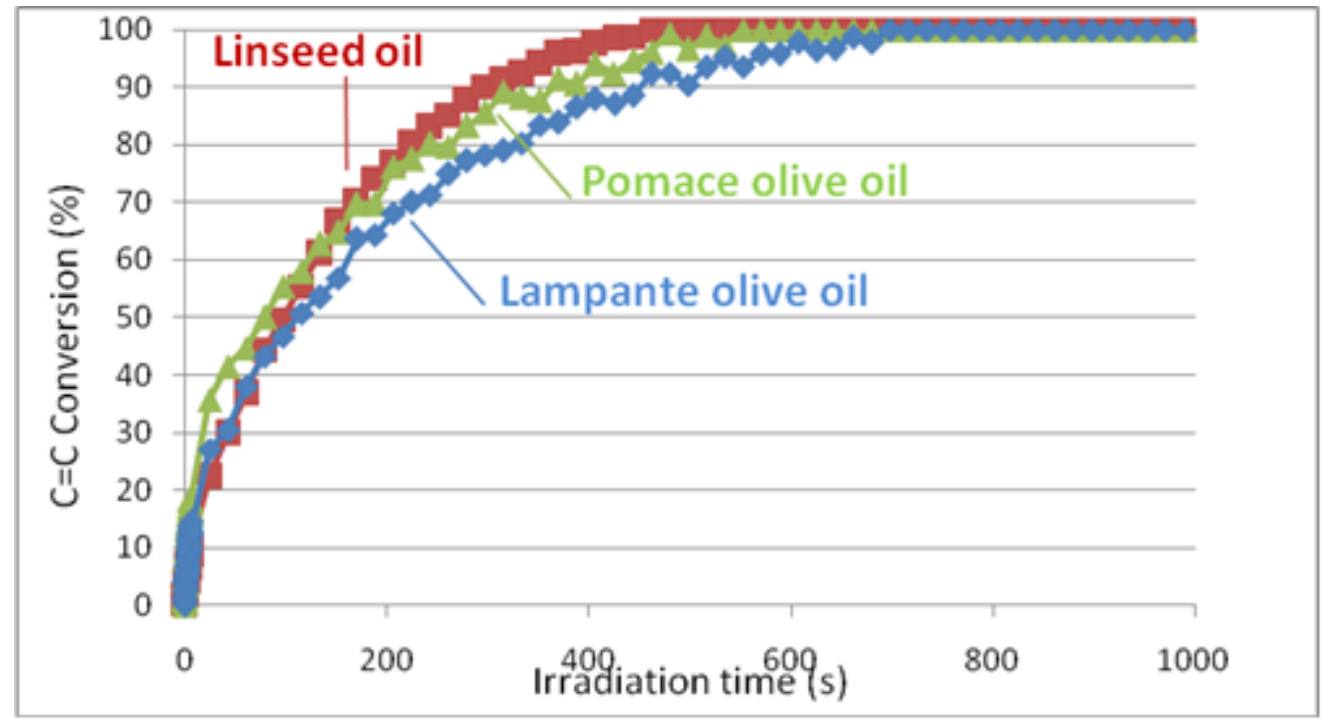

Figure 4 

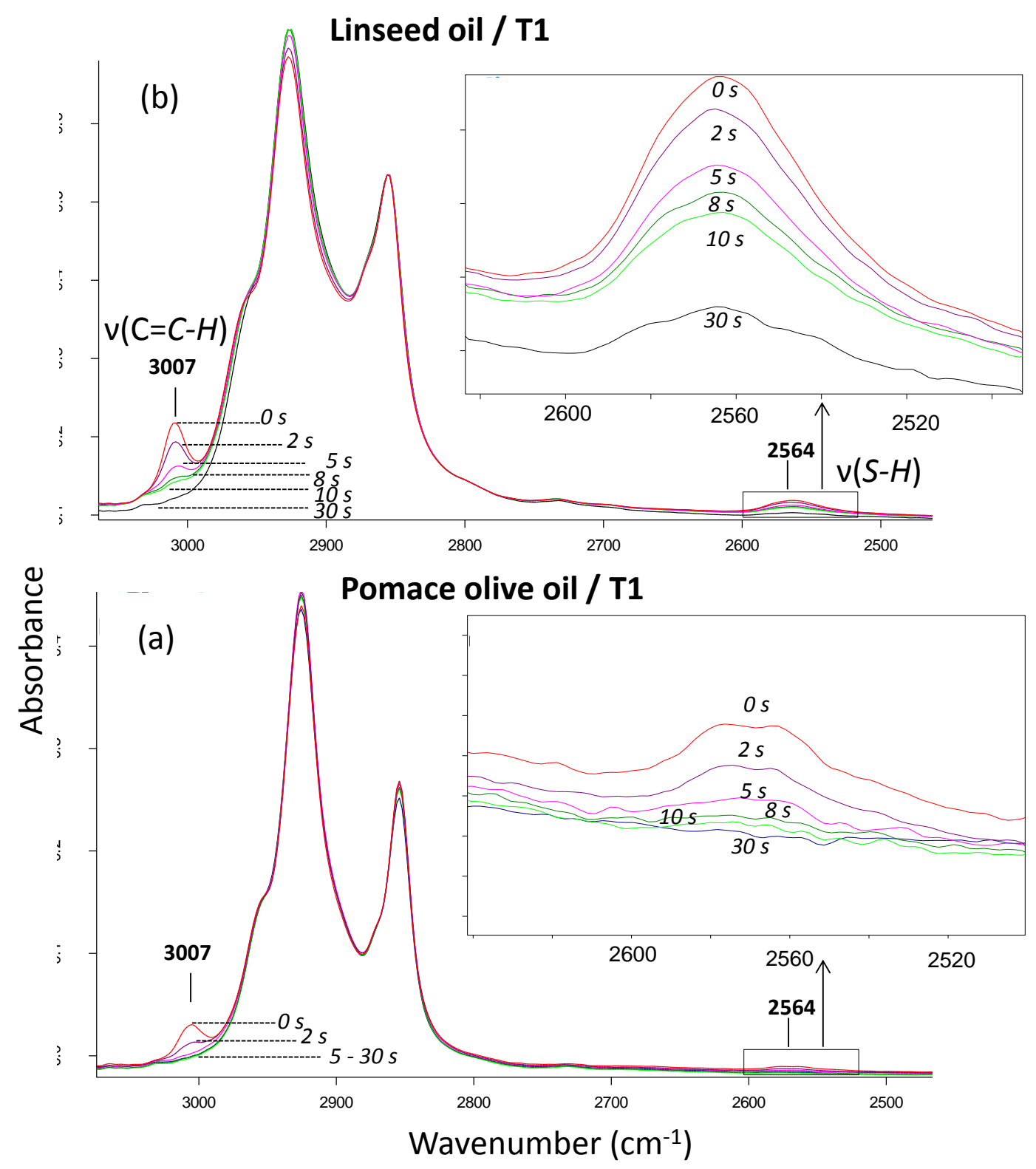

Figure 5 


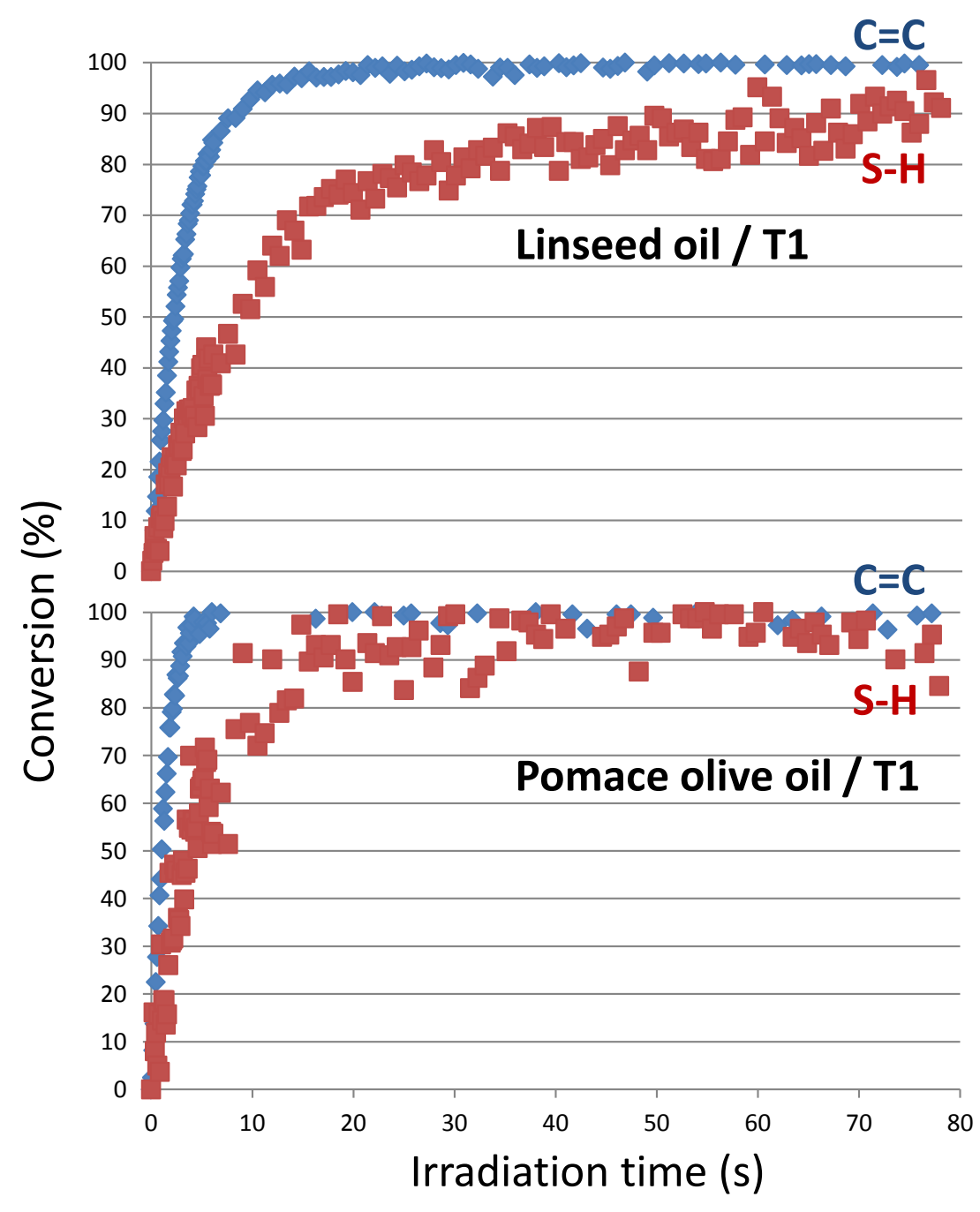

Figure 6 


\section{Graphical abstract}

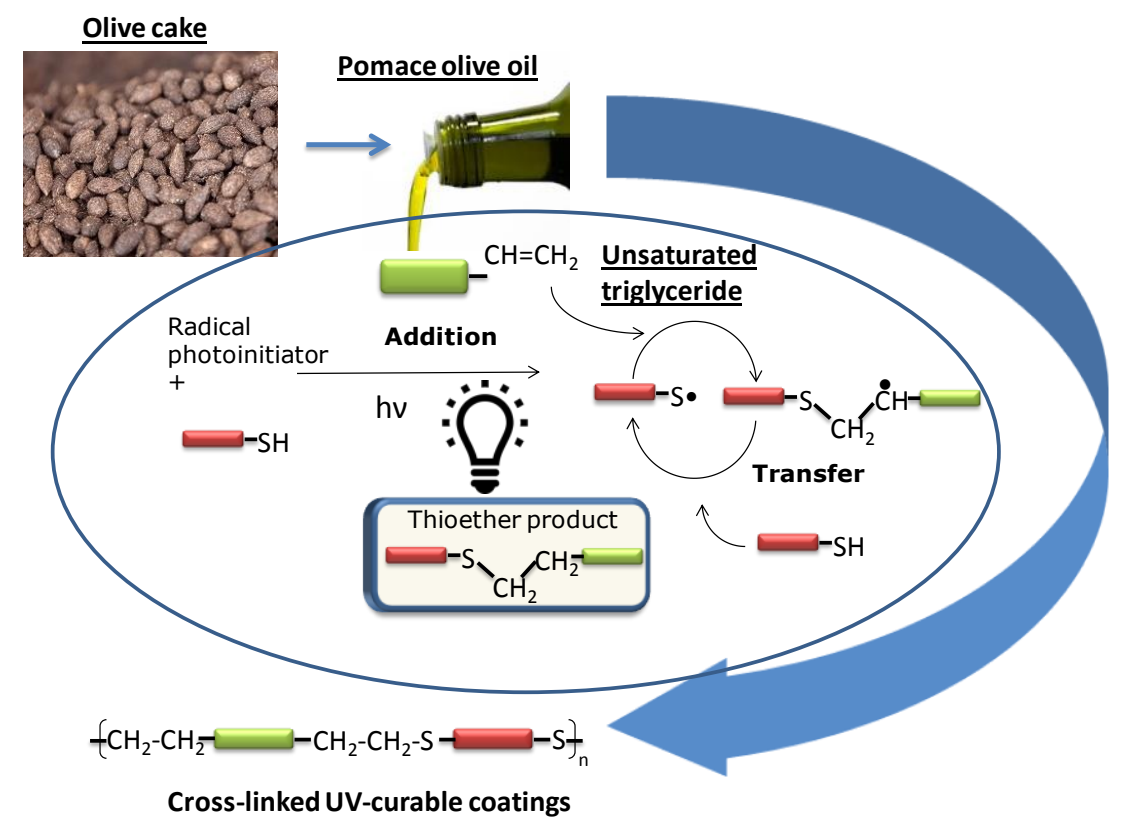

We report a method based on thiol-ene photopolymerization to prepare a new range of UVcurable films derived from the excess of low-grade pomace and lampante olive oils generated from the conventional extraction process of olive oil. 